\title{
Case Report Aneurysmal Bone Cyst of Talus
}

\author{
Dhan Bahadur Shrestha ${ }^{1}$, Bishnu Babu Thapa ${ }^{2}$, Dipendra Maharjan ${ }^{2}$, Kumar Basnet ${ }^{3}$, \\ Prabeen Ghimire ${ }^{1}$, Sijan Karki ${ }^{1}$
}

${ }^{1}$ Department of Emegency Medicine, Mangalbare Hospital, Urlabari-3; Morang, Nepal, ${ }^{2}$ Department of Orthopedics, Nepalese Army Institute of Health Sciences, Shree Birendra Hospital, Chhauni, Kathmandu, Nepal, ${ }^{3}$ Department of Emegency Medicine, Medical Officer, Shree Birendra Hospital, Chhauni, Kathmandu, Nepal

Address for correspondence: Dhan Bahadur Shrestha, Mangalbare Hospital, Urlabari-3; Morang, Nepal. Phone: +977-9849943388. E-mail: medhan75@gmail.com

\begin{abstract}
Aneurysmal bone cyst (ABC) of talus is rare benign, expansile, and osteolytic bone growth. Cyst contains blood mixed fluid lined with variable amount of osteolytic giant cells. This is common in epiphyseal ends of long bone and rare in small bones like talus. This 20 years' male having $A B C$ of talus managed with wide intralesional curettage and autologous bone graft mixed with synthetic bone graft.
\end{abstract}

Keywords: Aneurysmal bone cyst, Bone graft, Osteolytic giant cells

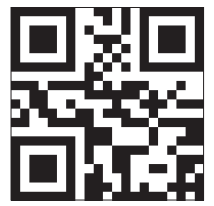

Quick Access Code

How to cite this article: Shrestha DB, Thapa BB, Maharjan D, Basnet $\mathrm{K}$, Ghimire P, Karki S. Aneurysmal Bone Cyst of Talus. Journal of Medical Research and Innovation. 2018;2(2):e000122.

DOI: 10.15419/jmri.122

Publication history:

Received: 02-05-2018

Accepted: 10-06-2018

Published: 05-07-2018

Editors: Dr. Shakti Goel

Copyright: Journal of Medical Research and Innovation. To get the copyrights or reprints, kindly mail us on editor@jmri.org.in

Funding: NIL

Conflict of Interest: NIL

\section{Introduction}

Aneurysmal bone cyst $(A B C)$ is destructive tumor-like benign, expansile, and osteolytic bone growth with cyst filled of blood and is rare and unusual in bone like talus. ${ }^{[1,2]}$ ABCs occur in the metaphysis of long bones though can occur in any bones, rarely occur in feet bones. Current hypothesis supports malformation of intraosseous arteriovenous channel with surrounding periosteum. ${ }^{[3,4]}$

There are some case reports on $A B C$ of talus in the literature though its rarity. There are no such reports available from Nepal. Here, we present a 20 years' male having $A B C$ of talus managed with wide intralesional curettage and autologous bone graft mixed with synthetic bone graft to fill the wide cavity.

\section{Case Report}

A 20 years' college student presented with pain and swelling of the left foot around ankle for 6 months which increased in the past 3 months. Pain is more in walking and exertion but no complete functional disability of ankle joint. He could go to college and was doing his activities of daily living though there was pain restricting his premorbid sports and outdoor activities. The patient gives a history of ankle sprain following which symptom persisted and even in later period its severity increased and presented to this hospital. At presentation, his visual analog score (VAS) for pain was $6 / 10$. His clinical examination of the left ankle revealed diffuse bony swelling on lateral aspect, about $2 \mathrm{~cm}$ dimension and associated with tenderness. There was mild restriction in dorsiflexion and plantar flexion in comparison to normal leg. Other history was unremarkable. Systemic examination, distal neurovascular examination, and other locoregional examinations and laboratory parameter were within normal range.

His X-ray of the left ankle joint [Figure 1(a)] revealed lytic lesion of the talus with some sclerotic changes with normal joint space. Hence, for further evaluation, we plan to go for computed tomography (CT) scan to define the lesion. His CT scan the left ankle [Figures 1(b-d)] revealed expanding lytic lesion of the talus involving dome, mid and posterior portion with cortical breach measuring $44 * 41 \mathrm{~mm}$ in size with intact ankle joint. Being CT scan was inconclusive, we plan to workup with magnetic resonance imaging left ankle [Figures $1(e, f)$ ] which showed multiloculated well-defined lesion of varying sizes in talus showing $T_{1}$ hypointensity and $T_{2}$ 

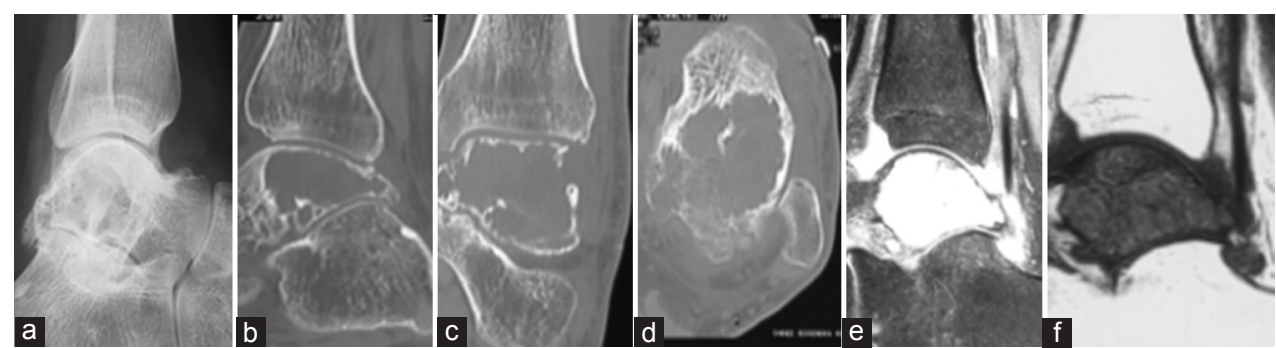

Figure 1: (a) Pre-operative lateral view of ankle showing lytic lesion of talus with sclerosis; (b) Sagittal; (c) coronal; (d) transverse slices of computed tomography ankle showing expanding lytic lesion of the talus involving dome, mid and posterior portion; (e) Pre-operative magnetic resonance imaging $T_{2}$ hyperintense; ( $f$ ) $T_{1}$ hypointense, multiloculated welldefined lesion in talus

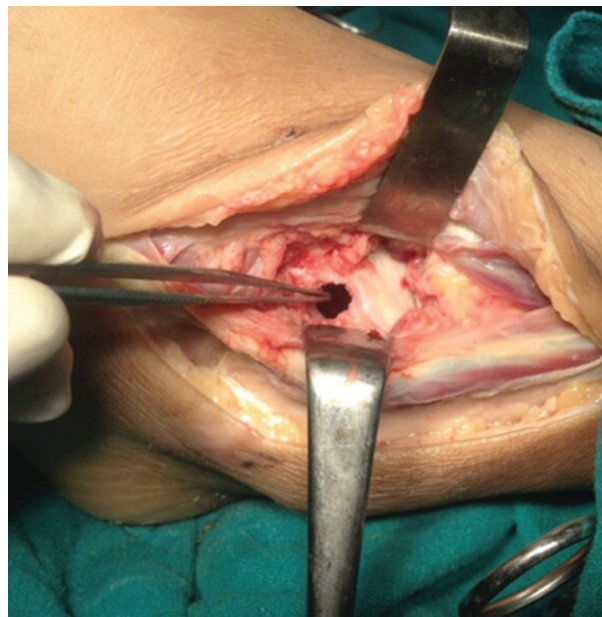

Figure 2: Intraoperative photograph showing curettage of lesion

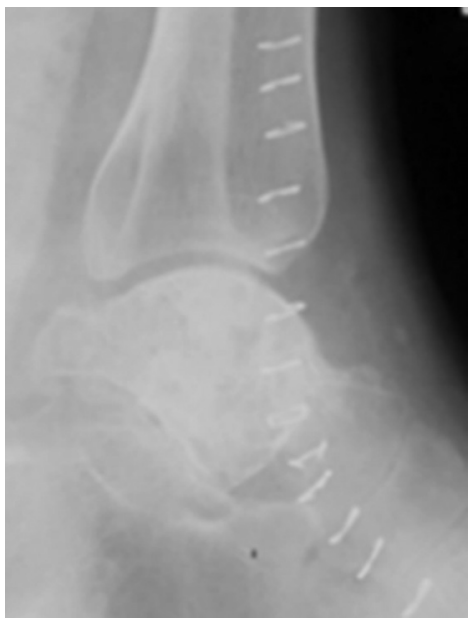

Figure 3: Post-operative imaging after curettage and grafting

hyperintensity giving fluid-fluid level appearance suggestive of $A B C$.

Before going to definitive management, we plan to go for biopsy of the lesion and histopathological examination (HPE) report of biopsy specimen showed necrotic bony fragment with fibrofatty tissue and occasional osteoclastic type of giant cells. Keeping the diagnosis as ABC of talus, we plan to go for curettage [Figure 2] and bone graft from iliac crest mixed with bone cement, based on recent management protocol for $A B C$ of talus. Later in post-operative period, the final HPE of curettage specimen revealed cystic spaces with blood-filled cysts, at places lined with giant cells, finding consistent with $A B C$.

In post-operative period, he was provided with general postoperative care with antibiotic and analgesics. His VAS score for pain was $3 / 10$ in the $7^{\text {th }}$ post-operative day. He was discharged after suture removal in the $2^{\text {nd }}$ week postoperatively and kept under regular follow-up. After surgical intervention, later, he was called on the $6^{\text {th }}$ week postoperatively, $3^{\text {rd }}$ month, $6^{\text {th }}$ month, and 1-year follow-up during which period his pain and discomfort and simple X-ray were [Figures 3 and 4] taken to evaluate graft uptake. His VAS score was $1 / 10$ in the $3^{\text {rd }}$ month, then $0 / 10$ thereafter. It is already more than a year postoperatively and the patient is doing absolutely fine in the last follow-up after a year post-operative.

\section{Pre-operative imaging}

Pre-operative lateral view of X-ray left ankle revealed lytic lesion with minimal sclerotic changes in talus. On further work-up with CT scan showed expanding lytic lesion of talus extending dome mid and posterior portion of talus with cortical breach $(44 * 41 \mathrm{~mm})$ with intact ankle joint space. On pre-operative MRI there was multiloculated well defined lesion in talus showing $\mathrm{T} 1$ hypointensity and $\mathrm{T} 2$ hyperintensity suggesting $\mathrm{ABC}$.

\section{Discussion}

Ankle and foot tumors though rare pathology, it is not uncommon in large tertiary centers. Among these, benign lesions are much more common so physicians dealing with foot lesions have tendency to miss malignant lesion in early stage. ${ }^{[5]} A B C$ is commonly encountered pathology, mostly of long bone. ${ }^{[3,6]}$ Among benign non-tumorous lesion encountered in feet, it is not so uncommon in large setting, but this entity affecting talus is rare. ${ }^{[2,5-7]} A B C$ is more common in 


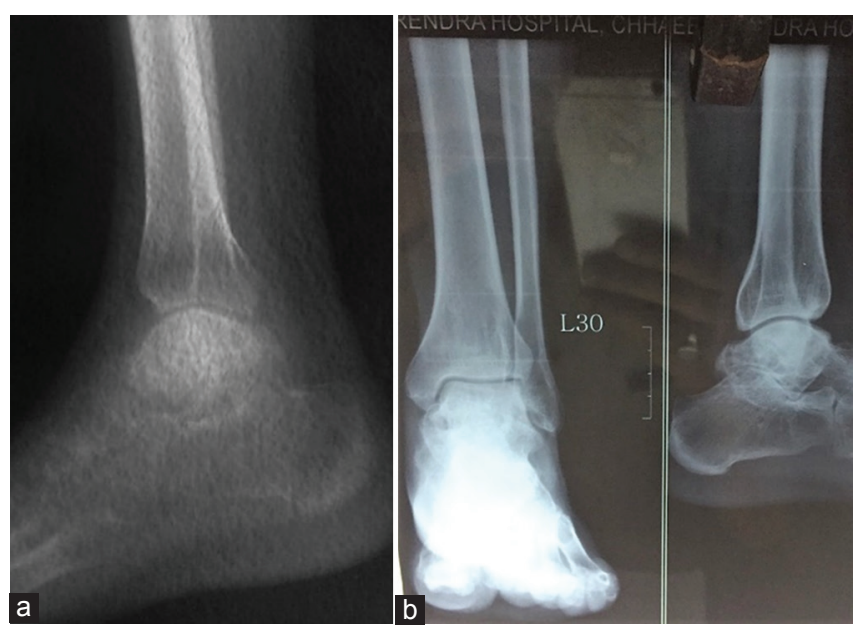

Figure 4: Follow-up photographs (a) 6-week post-operative, (b) 1-year post-operative

young individuals and is supposed to be due to arteriovenous malformation. ${ }^{[3,8]}$

Curettage with or without autologous or allograft bone graft is common modality, but only curettage has high rate of recurrence. ${ }^{[8]}$ Other modalities of treatment include partial or complete talectomy and curettage with cauterization following bone cement to fill the cavity. ${ }^{[7,9,10]}$ Although there are various options superiority of outcome of, one over another has not been studied at due to the rarity of the case. Although in our center, there is availability of arthroscopic facility in present days, we less frequently perform arthroscopy of ankle joint. In this case, due to thin cortex separating the cyst from the ankle joint, arthroscopic approach is not tried here.

\section{Conclusion}

Although $A B C$ of talus is rare benign lesion, it can be present in any health-care facility. The imaging modalities with the help of pre-operative biopsy can help to reach the diagnosis. Curettage of the lesion with autologous bone graft with or without synthetic bone is the convenient option for the management with functional recovery.

\section{Acknowledgment}

We would like to acknowledge our patient who was focus of the study and all hospital staffs who have contributed for care of this patient.

\section{References}

1. Luna AR, Fahandez-Saddi H, Garcia AV, Reina Cde J, Martin JV. Aneurysmal bone cyst in children involving infrequent locations. Report on two cases. Chir Organi Mov 2004;89:347-52.

2. Sharma S, Gupta P, Sharma S, Singh M, Singh D. Primary aneurysmal bone cyst of talus. J Res Med Sci 2012;17:1192-4.

3. Chowdhry M, Chandrasekar CR, Mohammed R, Grimer RJ. Curettage of aneurysmal bone cysts of the feet. Foot Ankle Int 2010;31:131-5.

4. Casadei R, Ruggieri $P$, Moscato $M$, Ferraro A, Picci P. Aneurysmal bone cyst and giant cell tumor of the foot. Foot Ankle Int 1996;17:487-95.

5. Ruggieri P, Angelini A, Jorge FD, Maraldi M, Giannini S. Review of foot tumors seen in a university tumor institute. J Foot Ankle Surg 2014;53:282-5.

6. Soreff J. Aneurysmal bone cyst of the talus. Acta Orthop Scand 1976;47:358-60.

7. Malawer MM, Vance R. Giant cell tumor and aneurysmal bone cyst of the talus: Clinicopathological review and two case reports. Foot Ankle 1981;1:235-44.

8. Biesecker JL, Marcove RC, Huvos AG, Mike V. Aneurysmal bone cysts: A clinicopathological study of 66 cases. Cancer 1970;26:615-25.

9. Shears E, Dehne K, Murata H, Abudu A, Grimer RJ, Tillman RM, et al. Healing of ungrafted bone defects of the talus after benign tumour removal. Foot Ankle Surg 2008;14:161-5.

10. Özer D, Er T, Aycan OE, Öke R, Coşkun M, Kabukçuoğlu YS. May bone cement be used to treat benign aggressive bone tumors of the feet with confidence? Foot 2014;24:1-5. 